\title{
Assessment of the Peripheral Microcirculation Using Computer-Assisted Venous Congestion Plethysmography in Post-Traumatic Complex Regional Pain Syndrome Type I
}

\author{
Matthias Schürmann ${ }^{a}$ Johannes Zaspela Georg Gradla Alexander Wipfel ${ }^{a}$ \\ Frank Christ $^{\text {b }}$
}

Departments of a Surgery, and ${ }^{\mathrm{b}}$ Anesthesiology, Ludwig Maximilians University of Munich, Germany

\author{
Key Words \\ Complex regional pain syndrome - Sympathetic reflex \\ dystrophy · Venous congestion plethysmography · \\ Microcirculation
}

\begin{abstract}
In complex regional pain syndrome type I (CRPS-I), edema of the affected limb is a common finding. Therefore, the changes in macro- and microcirculatory parameters were investigated to elucidate the underlying pathophysiology. Twenty-four patients with post-traumatic CRPS-I and 25 gender- and age-matched healthy subjects were examined by means of an advanced computer-assisted venous congestion strain-gauge plethysmograph. The recording of the volume response of the forearm to a stepwise inflation of an occlusion cuff placed at the upper arm enabled the calculation of the arterial blood flow into the $\operatorname{arm}\left(\mathrm{Q}_{\mathrm{a}}\right)$, the vascular compliance $(\mathrm{C})$, the peripheral venous pressure $\left(P_{v}\right)$, the isovolumetric venous pressure $\left(\mathrm{P}_{\mathrm{vi}} ;=\right.$ hydrostatic pressure needed to achieve net fluid filtration) and the capillary filtration capacity (CFC) - an index of microvascular permeability. The study revealed no difference in any of the parameters between the right and left hand of healthy subjects. In CRPS-I patients, however $\mathrm{O}_{\mathrm{a}}, \mathrm{P}_{\mathrm{v}}, \mathrm{P}_{\mathrm{vi}}$ and CFC were sig-
\end{abstract}

nificantly ( $p<0.01 / 0.001$ ) elevated in the affected arm $\left(\mathrm{Q}_{\mathrm{a}} 11.2 \pm 7.0 \mathrm{ml} \mathrm{min}^{-1} 100 \mathrm{ml}^{-1}, \mathrm{P}_{\mathrm{v}} 20.2 \pm 8.1 \mathrm{~mm} \mathrm{Hg}\right.$ ， $\mathrm{P}_{\mathrm{vi}} 24.7 \pm 4.2 \mathrm{~mm} \mathrm{Hg}$, CFC $0.0058 \pm 0.0015 \mathrm{ml} \mathrm{min}^{-1}$ $100 \mathrm{ml}^{-1} \mathrm{~mm} \mathrm{Hg}^{-1}$ ) compared to the unaffected arm $\left(\mathrm{Q}_{\mathrm{a}} 4.2 \pm 2.4 \mathrm{ml} \mathrm{min}^{-1} 100 \mathrm{ml}^{-1}, \mathrm{P}_{\mathrm{v}} 10.0 \pm 5.1 \mathrm{~mm} \mathrm{Hg}, \mathrm{P}_{\mathrm{vi}}\right.$ $13.2 \pm 3.7 \mathrm{~mm} \mathrm{Hg}$, CFC $0.0038 \pm 0.0005 \mathrm{ml} \mathrm{min}^{-1}$ $100 \mathrm{ml}^{-1} \mathrm{~mm} \mathrm{Hg}^{-1}$ ) and the values obtained in healthy controls $\left(Q_{a} 5.1 \pm 1.3 \mathrm{ml} \mathrm{min}^{-1} 100 \mathrm{ml}^{-1}, \mathrm{P}_{\mathrm{v}} 10.4 \pm 4.3\right.$ $\mathrm{mm} \mathrm{Hg}, \mathrm{P}_{\mathrm{vi}} 15.7 \pm 3.3 \mathrm{~mm} \mathrm{Hg}, \mathrm{CFC} 0.0048 \pm 0.0012 \mathrm{ml}$ $\mathrm{min}^{-1} 100 \mathrm{ml}^{-1} \mathrm{~mm} \mathrm{Hg}^{-1}$ ). Whereas the values in the unaffected arm of CRPS-I patients revealed no difference in $\mathrm{Q}_{a}, \mathrm{P}_{\mathrm{v}}$ and $\mathrm{P}_{\mathrm{vi}}$ but a lower CFC $(\mathrm{p}<0.01)$ compared to those from healthy controls. These results suggest profound changes in both macro- and microvascular perfusion in the affected arm of CRPS-I patients. The high CFC contributes to the edema formation, and combined with the elevated $\mathrm{P}_{\mathrm{vi}}$, they are in agreement with the hypothesis of an inflammatory origin of CRPS.

Copyright $\odot 2001$ S. Karger AG, Basel

\section{Introduction}

The complex regional pain syndrome type I (CRPS-I) is a frequent complication in surgical patients after trauma or operation. It is characterized by disproportionate

\begin{tabular}{ll}
\hline KARGER & ( ) 2001 S. Karger AG, Basel \\
Fax +4161306 1234 $34-1172 / 01 / 0385-0453 \$ 17.50 / 0$ \\
$\begin{array}{l}\text { E-Mail karger@karger.ch } \\
\text { www.karger.com }\end{array}$ & $\begin{array}{l}\text { Accessible online at: } \\
\text { www.karger.com/journals/jvr }\end{array}$
\end{tabular}

Dr. Matthias Schürmann
Chirurgische Klinik der Universität München, Klinikum Grosshadern
Marchioninistrasse 15, D-81377 München (Germany)
Tel. +49897095 0, Fax +49 8153990436
E-Mail mschuerm@gch.med.uni-muenchen.de 
pain, allodynia, vasomotor changes, decreased range of motion and edema in the affected limb [1]. In prospective studies in patients with distal radial fracture, the incidence of CRPS-I was $>20 \%$ [2-4]. The consequences of this disease on society may be considerable since CRPS-I causes severe complaints and longstanding disability in many patients.

Although the clinical picture and epidemiology of CRPS-I are well known, the underlying pathophysiology remains unclear. Until recently, an increased efferent sympathetic response following the initial injury was an often formulated hypothesis. Current placebo-controlled studies on the efficacy of therapeutic sympathicolysis [5] and the finding of diminished concentrations of norepinephrine in CRPS-I-affected extremities versus the unaffected side refute the hyperactive sympathetic theory [6]. By contrast, there is evidence of an upregulated sensitivity of $\alpha$-adrenoceptors for catecholamines in the affected extremity inducing CRPS-I. Already in 1900, Sudeck formulated another renascent hypothesis for the pathogenesis of CRPS-I which is based on the assumption of an exaggerated regional inflammatory response [7-10].

One of the major problems in the research on the pathophysiology of CRPS is the puzzling variety of symptoms that do not always occur in the same combination or succession. At the beginning of the disease, edema is one of the most frequent findings and can be observed in combination with other signs of inflammation (dolor, rubor, calor and functio laesa). There are several theories about the pathogenesis of edema in patients with CRPS-I. However, the mechanisms resulting in CRPS-I edema may differ from the pathogenesis of normal posttraumatic or postoperative edema, which are mediated following tissue damage. In CRPS-I patients, edemas appear in noninjured areas of the limb, and the development of edema is independent of the time the noxious event happened. Possible explanations for this phenomenon are an imbalance between postcapillary and precapillary vascular resistance causing an increase in peripheral hydrostatic pressure and/or an increase in capillary permeability and/ or capillary surface area $[11,12]$. Scintigraphic investigations of patients with CRPS-I of the hand support the latter hypothesis since an extravasation of macromolecules was found [13].

We investigated the changes in the peripheral circulation that led to the development of edema in patients with CRPS-I using a computer-assisted venous congestion plethysmograph, which enables the noninvasive assessment of macro- and microcirculatory parameters in the peripheral tissue [14-17].

\section{Patients and Methods}

\section{Patients}

Twenty-four patients ( 9 males and 15 females aged 36-85 years, average 56 years) with clinically diagnosed CRPS-I of the upper limb were examined. The diagnosis was established using the criteria of the 1993 Consensus Conference of the International Association for the Study of Pain [1] as well as the advanced differentiating criteria published by Brühl et al. [18]. In all patients, the disease was triggered by operation or trauma at the hands or wrists. In 2 cases, the duration of the disease was $>2$ years, in the remaining patients the average duration of disease was 63 days (range, 11-175 days). All patients exhibited a severe edema of the distal part of the arm with a side difference in hand volume of at least $60 \mathrm{ml}$. Differences in the etiology of edema were excluded, in particular there was no evidence of infection or delayed bone healing.

Twenty-five gender and age-matched healthy subjects, 12 males and 13 females, aged $23-85$ years (average 52 years), were examined in the same way as the CRPS-I patients. None of the patients and subjects had any evidence of vasospastic disease, occlusive atherosclerosis, diabetes mellitus or peripheral neuropathies. All patients received a standardized pain management (WHO protocols I/II) consisting of nonsteroidal anti-inflammatory drugs, metamizol or opioids according to their actual pain level. Examination was performed after informed consent of the patients and subjects was obtained.

\section{Clinical Examination}

All patients were examined clinically be means of a standardized protocol. Patients were seen by an experienced anesthesiologist, surgeon and neurologist in the interdisciplinary CRPS clinics. In addition to patient history, patients were examined with regard to pain, and sensory, motor and autonomic changes. The hand temperature was measured bilaterally with an infrared camera (Thermovision Scanner 900 SW-TE, AGEMA Infrared System, Sweden), and the hand volume was assessed quantitatively by means of a water immersion bath.

\section{Venous Congestion Plethysmography}

Venous congestion strain-gauge plethysmography (VCP) is a wellestablished noninvasive technique assessing microvascular parameters in peripheral human limbs. Initially, the VCP was mainly used to noninvasively determine arterial blood flow into a limb [19].

An advanced computer-assisted VCP, named Filtrass 2001, was used in the current study (DOMED, Gräfelfing, Germany). It enables a sensitive recording of limb circumference during venous congestion and an off-line computer-assisted calculation of microcirculatory parameters [16]. Filtrass enables to measures three macrovascular parameters: $\mathrm{Q}_{\mathrm{a}}\left(\mathrm{ml} \cdot \mathrm{min}^{-1} \cdot 100 \mathrm{ml}\right.$ tissue $\left.{ }^{-1}\right)$, which is the local arterial blood flow into the limb, $\mathrm{P}_{\mathrm{v}}(\mathrm{mm} \mathrm{Hg})$, the ambient local venous pressure and $\mathrm{C}\left(\mathrm{ml} \cdot \mathrm{mm} \mathrm{Hg}^{-1} \cdot 10^{-2}\right)$, the vascular compliance [14]. Two microvascular parameters, the capillary filtration capacity $(\mathrm{CFC})\left(\mathrm{ml} \cdot \mathrm{min}^{-1} \cdot 100 \mathrm{ml}^{-1} \cdot \mathrm{mm} \mathrm{Hg}^{-1}\right)$ and the isovolumetric venous pressure $\left(\mathrm{P}_{\mathrm{vi}} ; \mathrm{mm} \mathrm{Hg}\right)$, were also calculated. $\mathrm{CFC}$ is defined as the increase in fluid filtration into the tissue following an elevation of venous pressure [17]. $\mathrm{P}_{\mathrm{vi}}$ is an index of the relationship between the oncotic and hydrostatic forces at the microvascular interface and equals the capillary hydrostatic pressure that has to be exceeded to induce net fluid filtration into the interstitium.

Details on the assessment of CFC, $\mathrm{P}_{\mathrm{vi}}, \mathrm{P}_{\mathrm{v}}, \mathrm{Q}_{\mathrm{a}}$ and $\mathrm{C}$ have been published elsewhere [17]; therefore we will only outline the principle. 


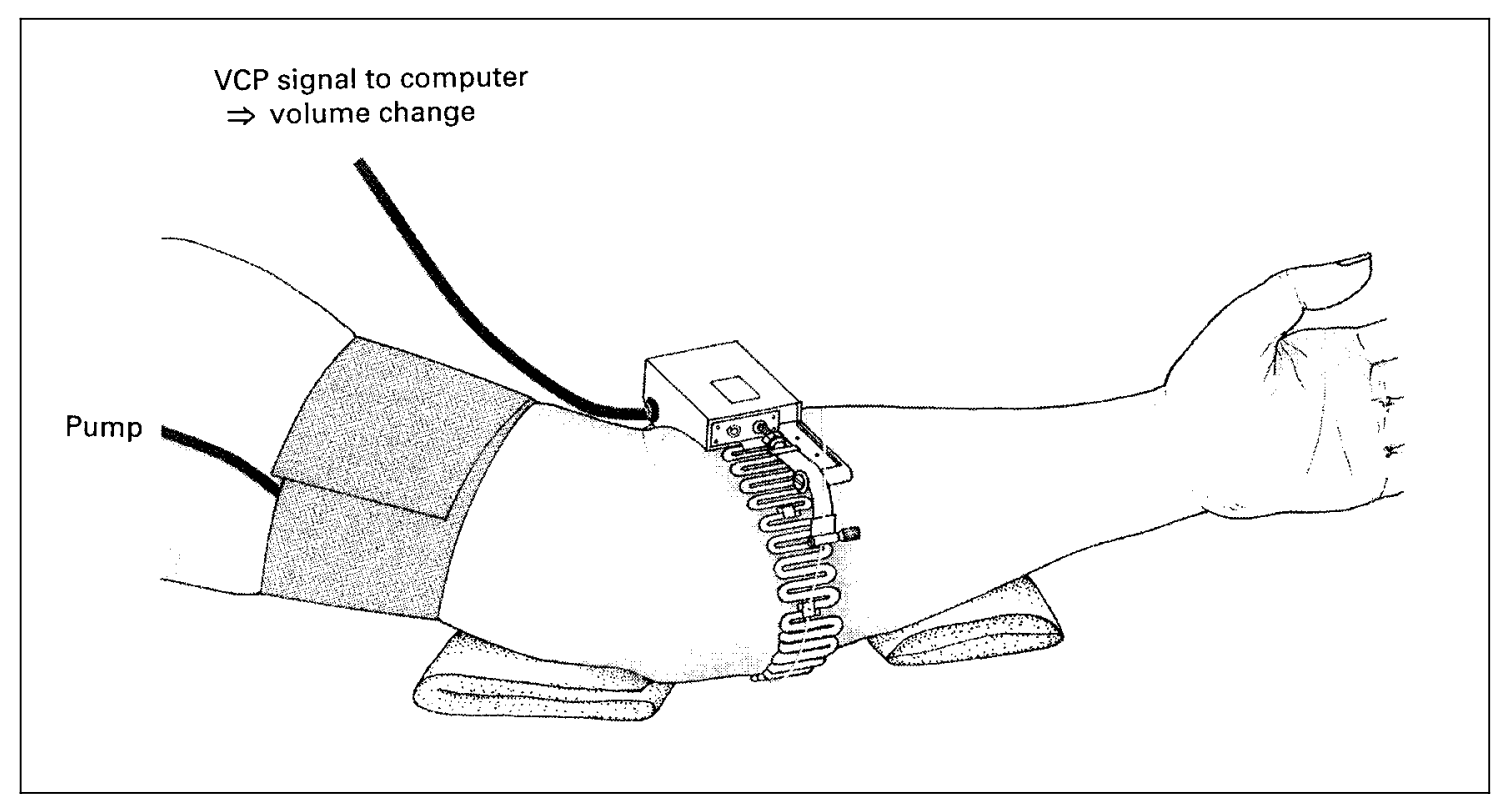

Fig. 1. The strain gauge system of the computer-assisted VCP (Filtrass 2001) positioned on the arm.

VCP is based on a stepwise inflation of an occlusion cuff, which is placed around the upper arm, leading to venous congestion and an increase in the volume in the forearm. This increase in limb circumference is measured with a highly sensitive strain gauge and is continuously recorded by a computer (fig. 1). The volume response to venous congestion consists of two components, vascular compliance and fluid filtration.

The initial rapid volume increase is attributable to the compliance of the postcapillary capacitance vessels and the surrounding tissue. Subsequently, a slow volume increase is noted, which is caused by fluid filtration into the interstitium. During the first component, the volume increases exponentially with a time constant of approximately $15 \mathrm{~s}$ in normal healthy subjects [17] until venous pressure just exceeds cuff pressure. Following the venous pressure increase, the normal fluid filtration into the interstitium increases to a level greater than the existing dynamic balance of Starling forces (isovolumetric venous pressure $\mathrm{P}_{\mathrm{vi}}$ ) and lymphatic drainage. Hence, net fluid filtration into the interstitial space results. Because of a low fluid filtration rate and a high extravascular capacity, the fluid filtration curve has an exponential time constant of over $800 \mathrm{~s}$ and can be approximated as a linear function over a time span of $240 \mathrm{~s}$. The two exponential functions of the volume response are distinguished by computer analysis, according to their different time constants $[15,16]$ (fig. 2a).

VCP Record Analysis. Each volume curve obtained during a single pressure step is evaluated separately. In each step, the filtration slope $\left(\mathrm{J}_{\mathrm{v}}\right)$ is estimated mathematically and subtracted from the record, the remainder equals the change in circumference due to the vascular complicance. In the negatively accelerated function of vascular complicance, the asymptotic value $\left(\mathrm{V}_{\mathrm{a}}\right)$ is estimated. Subsequently, $\mathrm{V}_{\mathrm{a}}$ of each pressure step is plotted as a function of the corresponding cuff pressure $\left(\mathrm{P}_{\text {cuff }}\right)$. The intercept of this function with the $\mathrm{x}$-axis is the actual venous pressure $\left(\mathrm{P}_{\mathrm{v}}\right)$ in the limb in the area of the strain gauge. The slope of this function equals the vascular compliance (C; fig. 2c) [14].
In the same way, the $\mathrm{J}_{\mathrm{v}}$ values of all pressure steps are plotted against the corresponding $\mathrm{P}_{\text {cuff. }}$ The slope of the linear regression curve based on the coordinates of $P_{\text {cuff }}$ and $J_{v}$ represents CFC. The interception with the $\mathrm{P}_{\text {cuff }}$ axis reflects $\mathrm{P}_{\mathrm{vi}}$, the isovolometric venous pressure (fig. 2b).

$\mathrm{Q}_{\mathrm{a}}$, the arterial blood flow into the limb, is assessed in an additional pressure step. The venous congestion pressure is raised to $50 \mathrm{~mm} \mathrm{Hg}$ and held for $10 \mathrm{~s}$ before deflation. The maximum blood flow is calculated within the first $5 \mathrm{~s}$ after inflation where the slope of the volume curve is the steepest. Within this time there is no evidence that the flow is altered by secondary effects as for example the veno-arterial reflex [20].

Study Protocol. All subjects and patients were examined in the same standardized way. Room temperature was kept within a range of $22-24^{\circ} \mathrm{C}$. Subjects had to rest on an examination bed in a comfortable supine manner for at least $15 \mathrm{~min}$ prior to the tests. Both arms were positioned in special armholders at the level of the right atrium for applying the occlusion cuff and the strain gauge. The cuff was fixed on the upper arm, while the gauge was applied to the area of the forearm with the maximum circumference (fig. 1).

After being attached to the extremity, the strain gauge systems are calibrated separately. This maneuver enables to adjust for differences in the volume of the edematous and non-edematous arm. The pressure step protocol starts with a baseline recording for $3 \mathrm{~min}$ to assess the initial volume changes in the limbs [16]. Then the $50 \mathrm{~mm}$ $\mathrm{Hg}$ pressure step for calculation of the arterial blood flow is applied. After deflation and storation of a stable baseline, six small pressure steps were carried out, starting from $10 \mathrm{~mm} \mathrm{Hg}$ to a final pressure of $70 \mathrm{~mm} \mathrm{Hg}$ in $10 \mathrm{~mm} \mathrm{Hg}$ steps, each step with a duration of $240 \mathrm{~s}$. All volume changes in the arms are recorded continuously by the computer system. The diastolic blood pressure never exceeded the cuff pressure in any subject. This modified pressure step protocol enabled to measure the microvascular parameters within $40 \mathrm{~min}$. 
Fig. 2. a Original VCP protocol with a 10second pressure step of $50 \mathrm{~mm} \mathrm{Hg}$ (blood flow measurement) followed by seven cumulating 240-second pressure steps each of $10 \mathrm{~mm} \mathrm{Hg}$. After mathematical separation of the total volume response during each pressure step into the vascular compliance component $\left(\mathrm{V}_{\mathrm{a}}\right)$ and the fluid filtration component $\left(\mathrm{J}_{\mathrm{v}}\right)$ both values were plotted against the corresponding cuff pressure. b The regression analysis revealed a linear function between $\mathbf{J}_{\mathrm{v}}$ and cuff pressure. The slope of the regression line represents $\mathrm{CFC}$ and the intercept at zero volume change the isovolumetric volume pressure $\left(\mathrm{P}_{\mathrm{vi}}\right)$. c The regression analysis produced a function of $\mathrm{V}_{\mathrm{a}}$ and cuff pressure. The slope of the regression line represents the vascular compliance $(\mathrm{C})$ and the intercept at zero volume change the ambient venous pressure $\left(\mathrm{P}_{\mathrm{v}}\right)$ in the limb.

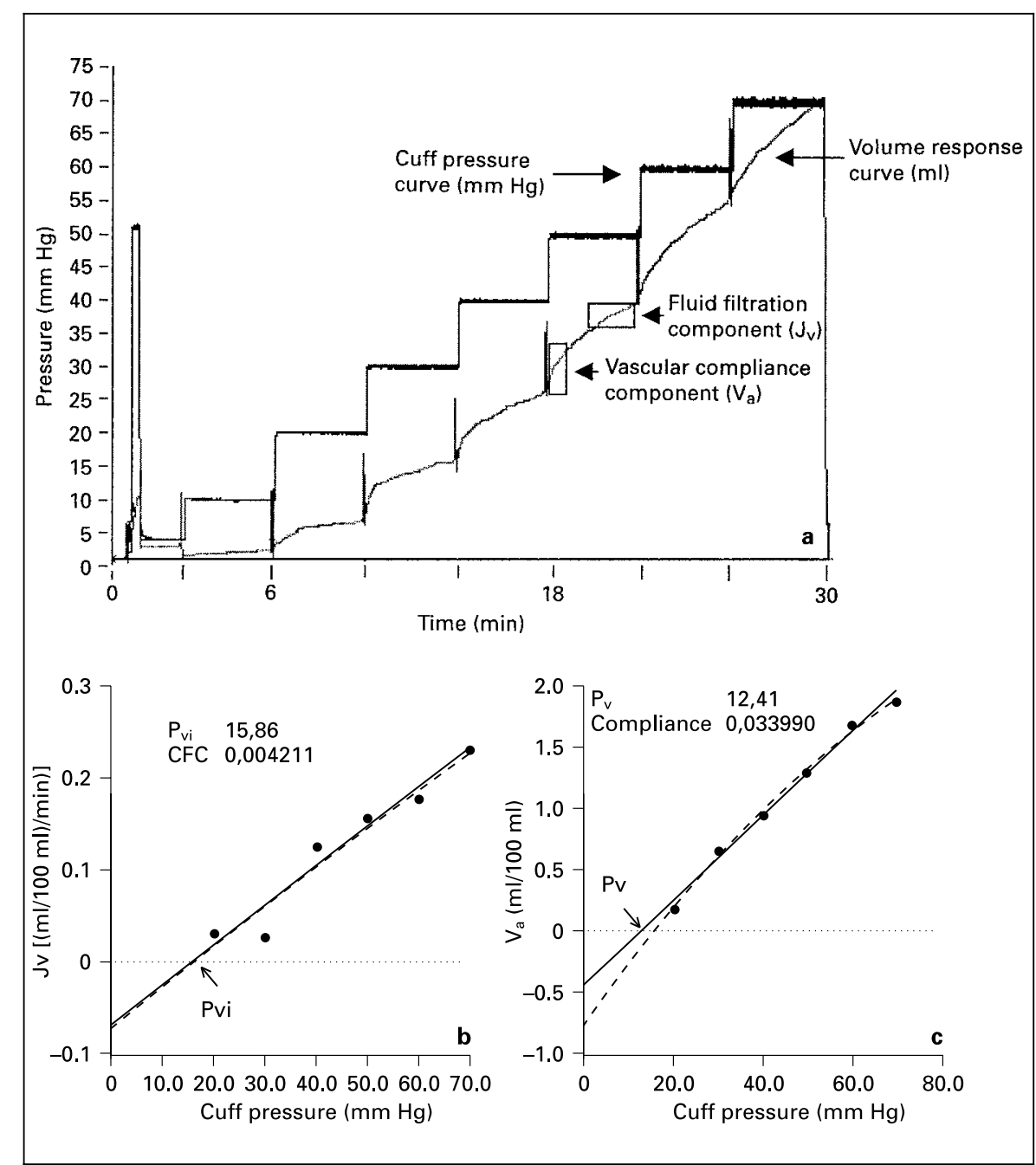

Statistical Analysis

The Kolmogorov-Smirnov test was chosen to assess equal distribution of all parameters. Statistical analysis was performed using the paired or unpaired Student's test and analysis of variance.

\section{Results}

\section{Clinical Findings}

The patients with CRPS-I presented a relatively homogeneous clinical picture consisting of spontaneous pain (mean value $2.9 \pm 1.5$, range $1-8$ on the visual analogue scale VAS 0-10), distinct impairment in their active range of motion (inability to make a first and DI-DV opposition), severely reduced grip strength $(<30 \%$ of the unaffected side) and edema with a bilateral volume difference of at least $60 \mathrm{ml}$. The assessment of skin surface tempera- ture with the infrared camera revealed an increased hand temperature of at least $1{ }^{\circ} \mathrm{C}$ in the affected hand in 14 cases $(58 \%)$. In 7 patients $(29 \%)$ there was no systematic temperature difference between the affected and unaffected hand, and in 3 cases (13\%) the affected hand $\left(\Delta<-1{ }^{\circ} \mathrm{C}\right)$ was colder. All patients presented with sudomotor abnormalities or skin color or skin trophic changes.

The majority of the CRPS-I patients ( 21 of 24 patients) and healthy subjects ( 21 of 25 subjects) were right-handed persons.

\section{Blood Flow}

In the healthy subjects, the blood flow showed no statistical difference between the left and the right hands, although in the right hand blood flow was slightly increased (table 1), which might be attributable to the over- 
Moreover, there was no statistical difference between the affected arm of the CRPS-I patients and the healthy subjects (tables 1, 2).

\section{Discussion}

The pathophysiology of CRPS-I is discussed controversially since there is no reliable proof for a single theory. There are two major aspects of the disease that lead to different hypotheses. First, the clinical appearance of CRPS-I supports the theory of a localized inflammation. This was already formulated by Mitchell in 1864 and Sudeck in 1900 and is supported by current scientific research [8, 21]. Oyen et al. [13], using scintigraphic techniques, showed an increased vascular permeability for macromolecules in the affected hand of CRPS-I patients, which is an important characteristic of inflammation [13]. In muscle specimens of CRPS-I patients, Van der Laan et al. [9] found an increase in lipofuscin pigment, atrophic muscle fibers and abnormal capillaries indicating oxidative stress [9]. The inflammation might be triggered by neuropeptides, since CRPS-I patients had markedly increased levels of bradykinin as well as calcitoningene-related protein and neuropeptide Y $[22,23]$.

In contrast to the hypothesis of an exaggerated inflammation in CRPS-I patients, many authors have focused on abnormalities in the peripheral or central nervous system in the discussion about the pathophysiology of the disease. Already in 1943, de Takats et al. [24] recognized the positive effects of sympathetic blockade to the complaints of CRPS-I patients. In many other studies, evidence in support of disturbances in the sympathetic nervous system was found. In particular, the sympatheticmediated vasoconstrictor skin reflexes appeared to be attenuated or abolished in CRPS-I patients [26-31].

The clinical picture of acute CRPS-I is characterized by blood flow abnormalities and edema. Edematous swelling of the distal and dorsal parts of the affected limbs is present in more than $90 \%$ of the cases [10, 30]. The appearance of this symptom is difficult to explain especially since there is often no relationship between the site of the inciting injury or operation and the location of the edema. Blumberg et al. [32] observed a positive influence of sympathetic blockade on the edema in CRPS-I patients even if these patients do not suffer from pain. They postulated a sympathetic origin of the edema similar to the sympathetically mediated pain in CRPS-I. They assumed that an imbalance between the sympathetic constrictor tone of postcapillary and precapillary vessels results in an elevated capillary filtration pressure, which leads to the plasma extravasation [33].

In contrast to this explanation, the edema might be produced by the microcirculatory changes accompanying a local inflammation, as suggested by Goris [7] in 1998 who interprets CRPS-I as a localized version of the systemic inflammatory response syndrome.

To determine the actual changes in limb microcirculation that lead to the development of edema in CRPS-I, the venous congestion plethysmography provides reliable data. The method has been validated in numerous studies and the reliability of the calculated parameters has been established [14-17, 34, 35]. This is also confirmed by the findings of the current study, since the bilateral examination of the hands in healthy subjects showed no side differences and a small standard deviation with regard to blood flow, $\mathrm{CFC}, \mathrm{P}_{\mathrm{v}}$ and $\mathrm{P}_{\mathrm{vi}}$ as well as vascular compliance.

The results of the VCP in 24 patients with CRPS-I revealed an increase in blood flow, $\mathrm{P}_{\mathrm{v}}, \mathrm{P}_{\mathrm{vi}}$ and $\mathrm{CFC}$ in the affected arm, compared to the unaffected arm as well as to the healthy subjects. There results might be systematically influenced by factors that interfere with the peripheral vasculature, such as the analgetic medication of the CRPS-I patients or different stages of the menstrual cycle of the study women. This potential risk for a data bias could not be sufficiently controlled, but seemed to be of minor importance in view of the high statistical significance of the observed differences. Moreover, since these are systemic events, they should also influence the microcirculation of the controlateral nonaffected arm. Different arm circumferences in CRPS-I patients due to ipsilateral edema have to be considered in the interpretation of the CFC and blood flow values. It is important to note that the strain gauge systems were adjusted and calibrated after they were placed onto the limb, therefore the initial volume differences have been accounted for. Edematous tissue is proportionally less vascularized than normal tissue. Hence an increased fluid filtration in response to an elevated hydrostatic presure, suggesting an elevated CFC, will be underestimated in an edematous limb. Our data revealed a distinct elevation in the CFC in the affected arm of CRPS-I patients, hence this observation seems valid.

\section{Blood Flow}

The elevated blood flow in the affected arm of CRPS-I patients was expected since a higher blood flow was shown in previous studies. Particularly CRPS-I patients with a short duration of the disease are supposed to exhibit a high blood flow in the affected hand accompanied by 
an elevation in skin temperature, which is also evident in our study [28]. However, there was no significant positive correlation between the temperature differences and the blood flow differences. In recent studies with laser Doppler or laser speckle imaging, skin blood flow in the affected arm of CRPS-I patients appeared not to be elevated despite a higher temperature in this limb compared to the contralateral side $[31,36]$. The blood flow measurements with VCP, however, mainly represent muscle blood flow, hence we suspect that the elevated flow in CRPS-I patients is a result of arteriovenous shunting in the muscles of the affected limb, which has already been observed by Matsumura et al. [36], using digital subtraction angiography.

\section{Capillary Filtration Capacity and Isovolumetric \\ Venous Pressure}

$\mathrm{CFC}$ describes the increase in fluid filtration following an elevation in the microvascular hydrostatic pressure in the limb resulting from venous congestion by means of a cuff applied to the proximal arm [17]. $\mathrm{P}_{\mathrm{vi}}$ reflects the cuff pressure, which has to be applied to induce a net fluid filtration into the limb. These values are determined by the balance of forces in the Starling equation [37].

$$
\mathbf{J}_{\mathrm{v}}=\mathrm{K}_{\mathrm{f}}\left[\left(\mathrm{P}_{\mathrm{c}}-\mathrm{P}_{\mathrm{i}}\right)-\sigma\left(\Pi_{\mathrm{c}}-\Pi_{\mathrm{i}}\right)\right]
$$

(equation 1)

where $\mathbf{J}_{\mathrm{v}}=$ fluid filtration into the interstitium, $\mathrm{P}=$ hydrostatic pressures, $\Pi=$ oncotic pressures, $\sigma=$ plasma protein permeability coefficient, $\mathrm{K}_{\mathrm{f}}=$ filtration coefficient, and subscripts $\mathrm{c}$ and $\mathrm{i}$ represent the capillary and interstitial space, respectively. With respect to equation 1, the higher CFC values found in the affected arm in patients suffering from CRPS-I in the present study could be caused by (1) an increased microvascular permeability to water ( $\mathrm{K}_{\mathrm{f}}$ filtration coefficient); (2) an increased surface area available for fluid filtration, and (3) an altered interstitial buffering capacity for the control of extracellular fluid volume. Many factors can cause an increase in $\mathrm{K}_{\mathrm{f}}$ such as high levels of free oxygen radicals, activated leukocytes or thrombocytes and several mediators of the inflammatory response, e.g. tumor necrosis factor $1 \alpha$ (TNF) and interleukins (IL). Previously, we have already shown a correlation between increased IL-6 levels, the adhesion molecule CD18 and increased CFC values [38]. In CRPS-I patients, hypoxia of peripheral tissue due to impaired microvascular perfusion may be responsible for local endothelial changes that lead to a capillary leakage.

On the other hand, sensory neuropeptides such as substance $\mathrm{P}$ (SP) and calcitonin-gene-related protein (CGRP) are also known to induce capillary leakage following release from sensory C-fibers that are antidromically activated [39]. Blair et al. [22] found elevated levels of CGRP in the peripheral blood of patients with CRPS-I [22], and our own unpublished data revealed elevated systemic levels of SP, TNF receptors and IL-8 in CRPS-I patients. Thus the increased capillary filtration capacity found in the current study might result from neurogenic inflammation, which has been suggested by several authors as a possible origin of CRPS-I.

Whilst we believe that an increased permeability to water could be the major factor in the pathophysiology of edema formation, and ultimately the impairment in tissue perfusion, other mechanisms which could also explain our findings have to be considered.

Potentially, an increased total surface area available for fluid filtration would also cause a higher CFC value. To our knowledge, no evidence has been found to date for such a change; by contrast, Matsumura et al. [36] showed increased arteriovenous shunting in the affected limbs of CRPS-I patients that might decrease the perfused vasculature in the peripheral tissue. No morphometric data, however, are currently available on the change in the actual number of microvessels perfused in patients suffering from CRPS-I, thus this remains mere speculation.

Changes in the interstitial buffering system may serve as an explanation for the observed edema in CRPS-I patients. Long-standing overcharge of capillary pressure and filtration may lead to a depletion of the interstitial buffering capacity [40]. The elevated peripheral venous pressure in our CRPS-I patients may contribute to such a mechanism, since it causes an increase in capillary hydraulic pressure and subsequently strains the drainage capabilities of the interstitium. While our data do not enable to draw any conclusions about the succession in the appearance of the observed phenomenon, this interpretation remains speculative. According to our own recent study about the clinical findings during the very early phase of CRPS-I, the afflicted patients present with the characteristic edema already 1 day after the inciting event [41]. This rapid increase in the interstitial fluid volume questions the contribution of potentially exhausted interstitial buffering systems.

However, the influences of a chronically reduced interstitial buffering capacity on the CFC parameter in our test setting are difficult to estimate. It is doubtful that the short-term increase in hydrostatic pressure, which is artificially produced by the applied venous congestion, may lead to substantial changes in the interstitial pressure. Moreover, capillary filtration is relatively insensitive to interstitial colloid osmotic pressure [42]. Thus the ob- 
served elevated CFC is more likely dependent on the endothelial permeability than on chronically altered interstitial hydraulic and osmotic pressure [43].

The reduction in CFC in the controlateral arm in CRPS-I patients is more difficult to interpret. We suggest that the previously shown upregulation of the $\alpha$-adrenoceptors in the nonaffected contralateral limb in CRPS-I patients may contribute to this phenomenon $[6,31,44]$.

The observed increase in $\mathrm{P}_{\mathrm{vi}}$ could be attributed to a local or systemic increase in plasma oncotic pressure. There have been no direct measurements of the plasma protein permeability coefficient $\sigma$ in patients suffering from CRPS-I. In the present study, venous plasma oncotic pressure was not assessed. We have previously established that an increased plasma oncotic pressure causes a similar change in $\mathrm{P}_{\mathrm{vi}}$ [35], hence this may explain the high $\mathrm{P}_{\mathrm{vi}}$ value found in the affected arm. Moreover, we have postulated that high values of $\mathrm{P}_{\mathrm{vi}}$ may be caused by a decrease in microvascular blood flow resulting from venular leukocyte/endothelial interaction. The flow-limited exchange increases the local oncotic pressure [34], thus a higher hydrostatic pressure (which is reflected in the $P_{v i}$ value) has to be generated to cause net fluid filtration. The significantly higher blood flow in the affected arm does not oppose this hypothesis since in CRPS-I an inhomogeneous perfusion may well exist in the affected limb similar to the changes seen in sepsis, where areas with the high flow are close to no-flow areas, thus causing functional shunting. The highest $\mathrm{P}_{\mathrm{vi}}$ values so far were found in patients suffering from sepsis and septic shock and correlated with patient outcome [34, 45], hence we would not rule out the possibility that the increased $\mathrm{P}_{\mathrm{vi}}$ values found in the affected limb reflect impaired microvascular perfusion despite a high arterial blood flow into the limb.

\section{Venous Pressure}

The venous pressure found in the healthy subjects and the non-affected arm of patients with CRPS-I are in keeping with previous invasive measurements $[14,46]$. The highly significant increase in $\mathrm{P}_{\mathrm{v}}$ in the affected limb has not been described before and is therefore surprising.
Moreover, the data provide evidence for the severe derangement of most hydrostatic forces in the affected limb. Chronically increased venous pressure causes edema once the capacity to increase lymph flow is exceeded [40]. Thus the edema seen in CRPS-I may be partially due to the elevated venous pressure. To which degree the increased $P_{v}$, however, is caused by the high blood flow and arteriovenous shunting remains to be determined.

In conclusion, the edema formation in CRPS-I is an expression for the insufficiency in the control of the interstitial fluid volume. We found a high arterial blood flow and elevated peripheral venous pressure suggesting arteriovenous shunting. Moreover, we provided evidence for a severe derangement in the Starling forces in the affected limb, which manifested itself by an elevated isovolumetric venous pressure. The elevated $\mathrm{CFC}$ in the affected limb of CRPS-I patients could be interpreted as an increase in the microvascular water permeability. An increase in the capillary permeability might be caused by local endothelial changes due to tissue hypoxia or the release of sensory neuropeptides in the context of a neurogenic inflammation. The changes detected in the microcirculation are in agreement with the hypothesis of a local inflammatory response in the affected limb of CRPS-I patients since they resemble the situation found in patients with the systemic inflammatory response syndrome. The new technique of a computer-assisted VCP enabled us to detect these changes easily and noninvasively in humans. We suggest that prospective studies of patients running the risk of developing CRPS-I should now establish the time course of these events during the very early phase of the disease, thus enabling the identification of etiological factors and of patients at risk of developing CRPS-I.

\section{Acknowledgments}

This study was financially supported by the Friedrich-Baur Stiftung München. Frank Christ, MD, discloses his financial interest in the filtrass 2001 apparatus.

\section{References}

1 Stanton-Hicks M, Jänig W, Hassenbusch S, Haddox JD, Boas R, Wilson P: Reflex sympathetic dystrophy: Changing concept and taxonomy. Pain 1995;63:127-133.

2 Atkins RM, Duckworth T, Kanis JA: Algodystrophy following Colles' fracture. J Hand Surg 1989;14-B:161-164
3 Atkins RM, Duckworth T, Kanis JA: Features of algodystrophy after Colles' fracture. J Bone Joint Surg 1990;72-B:105-110.

4 Field J, Atkins RM: Algodystrophy is an early complication of Colles' fracture - What are the implications? J Hand Surg 1997;22-B:178182.
5 Jadad AR, Carroll D, Glynn CY, McQuay HJ: Intravenous regional sympathetic blockade for pain relief in reflex sympathetic dystrophy: A systematic review and a randomized, doubleblind crossover study. J Pain Symptom Manage 1995;10:13-20. 
6 Drummond PD, Finch PM, Smythe GA: Reflex sympathetic dystrophy: The significance of differing plasma catecholamine concentrations in affected and unaffected limbs. Brain 1991; 114:2025-2036.

7 Goris RJA: Reflex sympathetic dystrophy: Model of a severe regional inflammatory response syndrome. World J Surg 1998;22:197202.

8 Sudeck P: Über die akute (trophoneurotische) Knochenatrophie nach Entzündungen und Traumen der Extremitäten. Dtsch Med Wochenschr 1902;28:336-338.

9 Van der Laan L, ter Laak HJ, Gabreels-Festen A, Gabreels F, Goris RJA: Complex regional pain syndrome type I (RSD) pathology of skeletal muscle and peripheral nerve. Neurology 1998;51:20-25.

10 Veldmann PHJM, Reynen HM, Arntz IE, Goris RJA: Signs and symptoms of reflex sympathetic dystrophy: Prospective study of 829 patients. Lancet 1993;342:1012-1016.

11 Blumberg H: A new clinical approach for diagnosing reflex sympathetic dystrophy; in Bond MR, Charlton JE, Woolf CJ (eds): Proceedings of the 6. World Congress on Pain. Amsterdam, Elsevier, 1991, pp 395-403.

12 Jänig W, Koltzenburg M: Possible ways of sympathetic-afferent interactions; in Jänig W Schmidt T (eds): Reflex Sympathetic Dystrophy. Weinheim, VCH, 1992, pp 213-243.

13 Oyen WJ, Arntz IE, Claessens RM: Reflex sympathetic dystrophy of the hand: An excessive inflammatory response? Pain 1993;55:151157.

14 Christ F, Gamble J, Baschnegger H, Gartside $\mathrm{B}$ : Relationship between venous pressure and tissue volume during venous congestion plethysmography in man. J Physiol 1997;503:463467.

15 Christ F, Bauer A, Brügger D, Oser D, Niklas M, Gartside IB: A novel, automatically calibrated, liquid metal-free measuring device for venous congestion plethysmography. J Vasc Res 1998;35:216.

16 Christ F, Bauer A, Brügger D, Niklas M, Gartside IB, Gamble J: Description and validation of a novel liquid metal-free device for venous congestion plethysmography. J Appl Physiol 2000;89:1577-1583.

17 Gamble J, Gartside IB, Christ F: A reassessment of mercury in silastic strain gauge plethysmography for microvascular permeability assessment in man. J Physiol 1993;464:407422.

18 Brühl S, Harden RN, Galer BS, Saltz S, Bertram B, Backonja M, Gayles R, Rudin N, Bhugra MK, Stanton-Hicks M: External validation of IASP diagnostic criteria for complex regional pain syndrome and proposed research diagnostic criteria. Pain 1999;81:147-154.
19 Whitney RJ: The measurement of volume changes in human limbs. J Physiol 1953;121: $1-27$.

20 Henriksen O, Sejrsen P: Local reflex in microcirculation in human skeletal muscle. Acta Physiol Scand 1977;99:19-26.

21 Mitchell SW, Morehouse CR, Keen WW: Gunshot Wounds and Other Injuries of the Nerves. Philadelphia, Lippincott, 1864.

22 Blair SJ, Chinthagada M, Hoppenstehdt D, Kijowski R, Fareed J: Role of neuropeptides in the pathogenesis of reflex sympathetic dystrophy. Acta Orthop Belg 1998;64:448-451.

23 Daemen MARC, Kurvers HAJM, Kitslaar PJEHM, Slaaf DW, Bullens PHJ, van den Wildenberg FAJM: Neurogenic inflammation in an animal model of neuropathic pain. Neurol Res 1998;20:41-45.

24 Hannington-Kiff JG: Intravenous regional sympathetic blocks; in Stanton-Hicks JG, Jänig W, Boas RA (eds): Reflex Sympathetic Dystrophy. Dordrecht, Kluwer, 1989, pp 113-124.

25 de Takats G, Miller D: Post-traumatic dystrophy of the extremities. Arch Surg 1943;46:469479.

26 Bej M, Schwartzmann R: Abnormalities of cutaneous blood flow regulation in patients with reflex sympathetic dystrophy as measured by laser Doppler fluxmetry. Arch Neurol 1991;48: 912-915.

27 Rosen L, Östergren J, Fagrell B, Stranden E: Skin microvascular circulation in the sympathetic dystrophies evaluated by videophotometric capillarscopy and laser Doppler fluxmetry. Eur J Clin Invest 1988;18:305-308.

28 Kurvers HAJM, Jacobs MJHM, Beuk RJ, Van den Wildenberg FAJM, Kitslaar PJEHM, Slaaf DW, Reneman RS: Reflex dystrophy: Result of autonomic denervation? Clin Sci 1994;87:663669.

29 Low PA Neumann C, Dyck PJ, Fealey RD, Tuck RR: Evaluation of skin vasomotor reflexes by using laser Doppler velocimetry. Mayo Clin Proc 1983;58:583-592.

30 Schürmann M, Gradl G, Fuerst H: A standardized bedside test for assessment of peripheral sympathetic nervous function using laser Doppler flowmetry. Microvasc Res 1996;52: 157-170.

31 Schürmann M, Gradl G, Andress HJ, Fürst H, Schildberg FW: Assessment of peripheral sympathetic nervous function for diagnosing early post-traumatic complex regional pain syndrome type I. Pain 1999;80:149-159.

32 Blumberg H, Griesser HJ, Hornyak M: Das distale posttraumatische Ödem - Symptom einer sympathischen Reflexdystrophie (Morbus Sudeck). Z Orthop 1992;130:9-15.

33 Blumberg H, Griesser H-J, Hornyak M: Neue Gesichtspunkte zur Klinik, Diagnostik und Pathophysiologie der sympathischen Reflexdystrophie (Morbus Sudeck). Unfallchirurgie 1990;16:95-106.
34 Christ F, Gartside IB, Kox WJ, Gamble J: The assessment of the microcirculatory effects of dobutamine using mercury in silastic strain gauge plethysmography in man. Postgrad Med J 1991;67(suppl 1):S42-S50.

35 Gamble J, Christ F, Gartside IB: The effect of passive tilting on microvascular parameters in the human calf: A strain gauge plethysmography study. J Physiol Lond 1997;498:541-552.

36 Matsumura H, Jimbo Y, Watanabe K: Haemodynamic changes in early phase reflex sympathetic dystrophy. Scand J Plast Reconstr Surg Hand Surg 1996;30:133-138.

37 Pappenheimer JR, Soto-Rivera A: Effective osmotic pressure of the plasma proteins and other quantities associated with the capillary circulation in the hindlimbs of cats and dogs. Am J Physiol 1948;152:471-491.

38 Chouker A, Thiel M, Baranow V, Meshkov D, Kotov A, Peter K, Messmer K, Christ F: Simulated microgravity, psychic stress, and immune cells in men: Observations during 120-day 6 degrees HDT. J Appl Physiol 2001;90:17361743.

39 Haegerstrand A: Inflammatory and trophic effects of sensory neuropeptides; in Jänig W, Schmidt T (eds): Reflex Sympathetic Dystrophy. Weinheim, VHC, 1992, pp 263-279.

40 Aukland K, Reed RK: Interstitial lymphatic mechanisms in the control of extracellular fluid volume. Physiol Rev 1993;73:1-78.

41 Schürmann M, Gradl G, Zaspel J, Kayser M, Löhr P, Andress HJ: Peripheral sympathetic function as a predictor of complex regional pain syndrome type I (CRPS I) in patients with radial fracture. Autonom Neurosci 2000;86: 127-134.

42 Hu X, Adamson RH, Liu B, Curry FE, Weinbaum S: Starling forces that oppose filtration after tissue oncotic pressure is increased. Am J Physiol Heart Circ Physiol 2000;279:H1724H1736.

43 Michel CC, Moyses C: The measurement of fluid filtration in human limbs; in Tooke JE, Smaje LH (eds): Clinical Investigations of the Microcirculation. Boston, Nijhoff, 1987, pp 103-126.

44 Arnold JMO, Teasell RW, MacLeod AP Brown JE, Carruthers SG: Increased venous alpha-adrenoceptor responsiveness in patients with reflex sympathetic dystrophy. Ann Intern Med 1993;118:619-621.

45 Christ F, Gamble J, Gartside IB, Kox WJ Increased microvascular water permeability in patients with septic shock, assessed with venous congestion plethysmography (VCP). Intensive Care Med 1998;24:18-26.

46 Brown E, Greenfield AD, Goei JS, Plassaras G Filling and emptying the low pressure blood vessels of the human forearm. J Appl Physiol 1966;21:573-582. 